\title{
Artigo/Article
}

\section{Identificação por PCR e sensibilidade a antifúngicos de isolados clínicos vaginais de Candida sp}

\author{
Identification by PCR and antifungal susceptibility of vaginal clinical Candida sp isolates \\ Izabel Almeida Alves ${ }^{1}$, Fernanda Pês de Camargo ${ }^{1}$ e Letícia Silveira Goulart ${ }^{1}$
}

\begin{abstract}
RESUMO
Introdução: A candidíase vaginal é uma condição que afeta um grande número de mulheres em idade fértil. Candida albicans é a espécie mais frequentemente isolada de secreção vaginal, entretanto, outras espécies mais resistentes às drogas antifúngicas podem ser isoladas de amostras clínicas vaginais. Métodos: Foram identificadas as espécies de 30 isolados vaginais de Candida sp por PCR utilizando o primer universal ITS4 e primers espécie-específicos para C. albicans, C. glabrata, C. tropicalis e C. krusei. A sensibilidade destes isolados frente à anfotericina B, fluconazol e voriconazol foi determinada pelo método de macrodiluição M27A2 do CLSI. Resultados: Através dos ensaios de PCR, 28 isolados foram caracterizados como C. albicans e 2 isolados apresentaram amplificação para os primers específicos de C. albicans e C. glabrata. A concentração inibitória mínima para anfotericina $B$ variou de $0,03 \mu \mathrm{g} / \mathrm{mL}$ a $0,25 \mu \mathrm{g} / \mathrm{mL}$, para o fluconazol de $0,125 \mu \mathrm{g} / \mathrm{mL}$ a $16 \mu \mathrm{g} / \mathrm{mL}$ e para o voriconazol de $0,03 \mu \mathrm{g} / \mathrm{mL}$ a $0,25 \mu \mathrm{g} / \mathrm{mL}$. Conclusões: A identificação de Candida ao nível de espécie através de ensaios de PCR deve ser relevante para o gerenciamento clínico destas infecções.
\end{abstract}

Palavras-chaves: Candida sp. Antifúngicos. PCR.

\begin{abstract}
Introduction: Vaginal candidiasis is a condition that affects innumerous fertile women. Candida albicans is the most frequently isolated species from vaginal discharge; however, other different species that are more resistant to antifungal drugs can be identified in vaginal clinical samples. Methods: The species of 30 vaginal Candida isolates was identified by PCR using the universal ITS4 primer and species-specific primers for C. albicans, C. glabrata, C. tropicalis and $C$. krusei. The sensitivity pattern to amphotericin $\mathrm{B}$, fluconazole and voriconazole was assessed using the CLSI M27-A2 macrodilution method. Results: The PCR assay revealed 28 C. albicans and 2 samples showed amplification for C. albicans and C. glabrata primers. The minimum inhibitory concentration for amphotericin B ranged from $0.03 \mu \mathrm{g} / \mathrm{mL}$ to $0.25 \mu \mathrm{g} /$ $\mathrm{mL}$, for fluconazole from $0.125 \mu \mathrm{g} / \mathrm{ml}$ to $16 \mu \mathrm{g} / \mathrm{mL}$ and for voriconazole from $0.03 \mu \mathrm{g} / \mathrm{mL}$ to $0.25 \mu \mathrm{g} / \mathrm{m}$. Conclusions: Identification at Candida species level by PCR assay could be relevant for clinical management of these infections.
\end{abstract}

Key-words: Candida sp. Antifungal. PCR.

1. Curso de Farmácia Bioquímica Clínica, Universidade Regional Integrada do Alto Uruguai e das Missões, Santo Ângelo, RS.

Endereço para correspondência: Acad. Izabel Almeida Alves. Campus Universitário/UFSM. Faixa de Camobi Km 9/Prédio 20/Sala 4139, 97105-900 Santa Maria, RS

Tel: 5555 3220-8906

e-mail: izabelalmeida@hotmail.com

Recebido para publicação em 14/11/2009

Aceito em 14/05/2010

\section{INTRODUÇÃO}

A candidíase vaginal afeta uma elevada proporção de mulheres em idade adulta, estima-se que aproximadamente $75 \%$ destas apresentem pelo menos um episódio de vulvovaginite fúngica em sua vida, onde 40 a $50 \%$ vivenciam novos surtos e $5 \%$ tornam-se recorrentes. A espécie isolada mais frequente de secreções vaginais continua sendo Candida albicans, entretanto, outras espécies também estão envolvidas neste tipo de infecção ${ }^{1,2}$.

O método convencional para identificação de espécies de Candida é baseado em teste de assimilação e fermentação de açúcares, análise morfológia da colônia, uso de meios cromogênicos, painéis enzimáticos e sistemas automatizados ${ }^{3-5}$. A fim de minimizar as limitações da fenotipagem, métodos de biologia molecular foram adaptados para serem utilizados na identificação de espécies de Candida $a^{6,7}$. Goebel ${ }^{8}$ padronizou um PCR espécieespecífico para determinar espécie de Candida. Este PCR espécie-específico consiste na amplificação das regiões transcritas internas 1 e 2 do gene do rRNA das espécies de Candida. Nesta técnica, foram utilizados 7 primers espécie-específicos e 1 primer universal, o qual anela em uma região do gene rRNA 28S. Estes primers identificam espécies de C. lusitanie, C. parapsilosis, C. tropicalis, C. albicans, C. krusei, C. glabrata e C. guilliermondii.

A resistência aos antifúngicos, tem representado um grande desafio para a clínica, frente às dificuldades observadas no tratamento da candidíase. Este aumento pode ser decorrente do uso de terapias seletivas com doses inadequadas ou devido ao uso crescente desses fármacos na profilaxia de infecções fúngicas o que pode condicionar a seleção da resistência clínica ${ }^{9}$. Devido ao aumento das infecções fúngicas oportunistas, o National Committee for Clinical Laboratory Standards (NCCLS) atual Clinical and Laboratory Standards Institute (CLSI) estabeleceu um subcomitê para padronizar a metodologia capaz de avaliar a suscetibilidade 
in vitro das leveduras ${ }^{10}$. A determinação da atividade dos antifúngicos possibilita realizar uma correlação entre atividade in vitro e resposta clínica, sendo possível desta forma, monitorar a resistência aos antifúngicos no curso do tratamento clínico ${ }^{11}$. O objetivo do presente trabalho foi identificar as espécies de Candida sp isoladas da mucosa vaginal por PCR e avaliar o perfil de suscetibilidade frente a anfotericina $\mathrm{B}$, ao fluconazol e ao voriconazol.

\section{MÉTODOS}

\section{Microrganismos estudados e condições de cultivo}

Foram utilizados neste estudo trinta isolados vaginais de Candida sp e as cepas padrões Candida albicans ATCC 18804 e Candida glabrata ATCC 2001. Os isolados clínicos foram obtidos de swabs coletados da mucosa vaginal de pacientes com sintomas de candidíase vulvovaginal, atendidas em um serviço de ginecologia do Município de Santo Ângelo, Rio Grande do Sul, no período de fevereiro a maio de 2007. A amostragem não foi populacional e, sim, proveniente do serviço de ginecologia, isto é, por demanda espontânea. As coletas foram realizadas por um médico ginecologista e os critérios empregados para caracterizar infecção foram prurido, edema, eritema na vulva e vagina e presença de fluxo vaginal grumoso aderente às paredes vaginais. As pacientes que participaram da pesquisa apresentaram adesão voluntária, seguida de autorização documentada através da assinatura do termo de consentimento livre esclarecido.

Os swabs da mucosa vaginal foram semeados ágar Sabouraud (Himedia, Mumbai, India) e incubados a $37^{\circ} \mathrm{C}$ por 48 horas. Colônias isoladas das leveduras foram identificadas de acordo com características macromorfológicas e micromorfológicas pela técnica de microcultivo em ágar Fubá (Oxoid, Basingstok, UK).

\section{Determinação das espécies por PCR}

Extração de DNA: o DNA genômico foi extraído conforme o método descrito por Crestani ${ }^{12}$. Os isolados foram semeados em ágar Saboraud por $24-48$ horas a $37^{\circ} \mathrm{C}$. As colônias foram recolhidas e adicionados a um microtubo contendo $500 \mu \mathrm{L}$ de tampão de lise celular ( $\mathrm{NaCl}$,15M; Tris - HCl 50M; EDTA 10mM; SDS - 2\%; pH 8 ) e este foi incubado a $65^{\circ} \mathrm{C}$ por uma hora. Após, foram adicionados $500 \mu \mathrm{L}$ de fenol/clorofórmio (1:1) e misturado em vórtex por 15 minutos. Este foi centrifugado por 15 minutos a 13000rpm e logo retirado a suspensão aquosa e adicionado a um novo microtubo. A suspensão que continha DNA foi adicionado $400 \mu \mathrm{l} \mathrm{de} \mathrm{fenol,} \mathrm{misturado} \mathrm{em} \mathrm{vórtex} \mathrm{por}$ 5 minutos e centrifugados por 15 minutos a $13000 \mathrm{rpm}$, a fase aquosa formada, foi submetida a outro processo de extração com $400 \mu$ de fenol. Ao sobrenadante foi adicionado $1 \mathrm{~mL}$ de etanol absoluto e este foi armazenado uma hora a $-20^{\circ} \mathrm{C}$. Após uma centrifugação por 15 minutos a $13000 \mathrm{rpm}$, o sedimento foi lavado com etanol $70 \%$ gelado, seco a temperatura ambiente e ressuspendido em $80 \mu \mathrm{L}$ de Tris - EDTA. Ao material foi tratado com $3 \mu \mathrm{l}$ de RNAse (Invitrogen, Carlsbad, CA) na concentração de $50 \mu \mathrm{g} / \mathrm{mL} 30$ minutos a $37^{\circ} \mathrm{C}$. A qualidade do DNA foi verificada visualmente sob luz UV após eletroforese em gel de agarose $0,8 \%$ corado com $0,5 \mu \mathrm{g} / \mathrm{mL}$ de brometo de etídio. Os microtubos contendo o DNA foram armazenados a $-20^{\circ} \mathrm{C}$.

\section{PCR espécie-específico}

O método de PCR utilizado para a identificação das espécies de Candida foi baseado no protocolo descrito por Goebel ${ }^{8}$. A reação de amplificação foi realizada em um volume final de $50 \mu \mathrm{L}$ contendo 10 a 20ng de DNA, 10mM Tris $\mathrm{HCl} \mathrm{pH} 8,3 / 50 \mathrm{mM} \mathrm{KCl}, 1,5 \mathrm{mM} \mathrm{MgCl}_{2}$, $0,8 \mathrm{mM}$ de desoxirribonucleotídeo, $0,8 \mu \mathrm{L}$ de cada primer $(20 \mathrm{pmol} / \mu \mathrm{L})$ e 1 U de Taq platinum DNA polimerase (Invitrogen, Carlsbad, CA). As condições para a realização deste PCR foram: desnaturação inicial de $94^{\circ} \mathrm{C}$ por 3 minutos, 35 ciclos de desnaturação de $94^{\circ} \mathrm{C}$ por um minuto, anelamento de $63^{\circ} \mathrm{C}$ por um minuto, extensão de $72^{\circ} \mathrm{C}$ por um minuto e extensão final de $72^{\circ} \mathrm{C}$ por 5 minutos. Os produtos de amplificação foram analisados em gel de agarose $1 \%$ corado com $0,5 \mu \mathrm{g} / \mathrm{mL}$ de brometo de etídio e visualizados sob luz UV.

Os primers utilizados foram construídos por $\mathrm{Li}$ et al ${ }^{13}$ com base nas sequências disponíveis no GenBank do espaçador transcrito interno (ITS) 1 e 2. São eles: CT (C. tropicalis, 5'-AAG AAT TTA ACG TGG AAA CTT A-3'), CA (C. albicans, 5'- TCA ACT TGT CAC AGA TTA TГ-3'), CK (C. krusei, 5'- GAT TTA GTA CTA CAC TGC GTC A-3'), CGLA (C. glabrata, 5'- CAC GAC TCG ACA CTГ TCT АAT T-3') e o primer universal ITS4 (5'- TCC TCC GCT TAT TGA TAT GC-3'). Os ensaios de PCR geram produtos de amplificação de $402 \mathrm{pb}$ para C. albicans, $632 \mathrm{pb}$ para C. glabrata, $475 \mathrm{pb}$ para C. krusei e de $149 \mathrm{pb}$ para C. tropicalis.

\section{Testes de suscetibilidade a antifúngicos}

Os testes de suscetibilidade a antifúngicos foram realizados conforme o protocolo $\mathrm{M}-27 \mathrm{~A} 2$ do $\mathrm{CLSI}^{11}$, sendo realizada a técnica de macrodiluição frente aos antifúngicos anfotericina B (Wyeth), fluconazol (Biolab Saws) e voriconazol (Pfizer). O meio de cultura utilizado foi o RPMI 1640 (Sigma-Aldrich) tamponado com ácido morfopropileno sulfônico (MOPS) 1,65M pH 7,2. Os fármacos foram conservados sob refrigeração e ao abrigo da luz até o momento do uso. As diluições dos antifúngicos foram realizadas com o meio RPMI 1640 a fim de se obter nos tubos testes concentrações que variam de 16 a $0,03 \mu \mathrm{g} / \mathrm{mL}$ para anfotericina B e de 64 a $0,125 \mu \mathrm{g} /$ $\mathrm{mL}$ para o fluconazol. Os inóculos foram preparados a partir de colônias com crescimento de $24 \mathrm{~h}$ em meio de ágar Saboraud as quais foram ressuspendidas em solução salina estéril, a fim de se obter uma turbidez correspondente a $1 \times 10^{6}$ a $5 \times 10^{6}$ células por $\mathrm{mL}$. Esta suspensão foi diluída 1:100, seguida de uma nova diluição 1:20 em meio líquido RPMI 1640. Volumes de $0,1 \mathrm{~mL}$ de cada uma das diferentes concentrações de agente antifúngico foram dispensados em tubos de ensaio de $12 \times 75 \mathrm{~mm}$, após foram acrescentados $0,9 \mathrm{~mL}$ do inóculo padronizado. Os tubos foram incubados a $37^{\circ} \mathrm{C}$ por $48 \mathrm{~h}$, para posterior determinação da concentração inibitória mínima (CIM). O critério de leitura considerou que a CIM seria a menor concentração capaz de inibir $80 \%$ do crescimento para os azólicos e $100 \%$ para anfotericina B.

\section{Ética}

O presente estudo foi aprovado pelo Comitê de Ética em Pesquisa da Universidade Regional Integrada do Alto Uruguai das Missões, sob protocolo $n^{\circ}$ 032-4/THC/06.

\section{RESULTADOS}

Os ensaios de PCR permitiram identificar as espécies das amostras como 28 (93,3\%) C. albicans e 2 (6,7\%) foram caracterizadas como C. albicans e C. glabrata, ou seja, apresentaram amplificação tanto para o primer CA, quanto para o primer CGLA. As Figuras 1 e 2 apresentam os produtos de amplificação obtidos com o PCR espécieespecífico. Nenhum dos isolados apresentou amplificação com os primers $\mathrm{CT}$ e $\mathrm{CK}$, os quais permitem identificar C. tropicalis e C. krusei, respectivamente. Os ensaios foram realizados em duplicata, a fim de garantir maior confiabilidade dos resultados. 


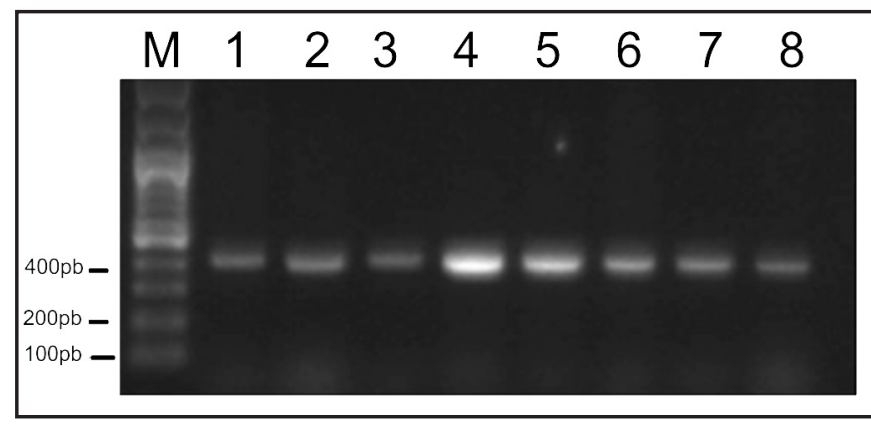

FIGURA 1 - Reação em cadeia da polimerase utilizando primers (ITS4 e CA) para identificação de C. albicans. M-marcador de peso molecular; linha 1- C. albicans ATCC 18804; linhas 2 a 8 - isolados 1, 2, 3, 4, 5, 16, 26.

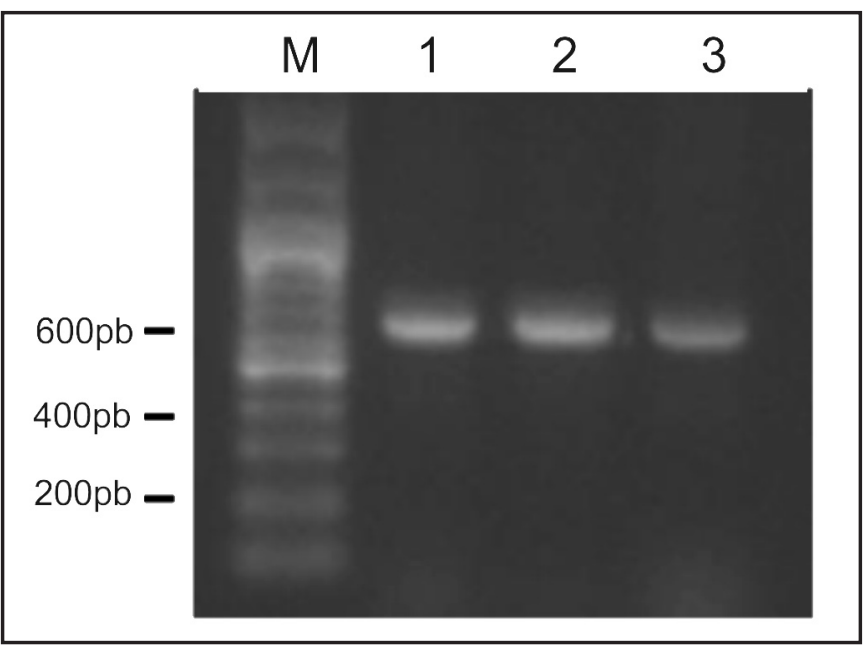

FIGURA 2 - Reação em cadeia da polimerase utilizando primers (ITS4 e CG) para identificação de C. glabrata. M-marcador de peso molecular; linha 1 C. glabrata ATCC 2001; linhas 2 e 3 - isolados 16 e 26.

Para os testes de suscetibilidade foram utilizados apenas 28 isolados, uma vez que foram excluídos destes ensaios as duas amostras que apresentaram duas espécies (C. albicans e C. glabrata) concomitantes. Após a realização dos testes de suscetibilidade frente à anfotericina $\mathrm{B}$, determinou-se que todos os isolados foram sensíveis a este poliênico. As CIMs para este antifúngico variaram de 0,03 a $0,25 \mu \mathrm{g} / \mathrm{mL}$ sendo que a $\operatorname{CIM}_{50}$ (concentração inibitória mínima para $50 \%$ das amostras testadas) foi de $0,06 \mu \mathrm{g} / \mathrm{mL}$ e a $\mathrm{CIM}_{90}$ (concentração inibitória mínima para $90 \%$ das amostras testadas) foi de $0,25 \mu \mathrm{g} / \mathrm{mL}$ (Tabela 1). Os testes de suscetibilidade ao fluconazol, também caracterizaram todos os isolados como sensíveis a este azólico. As CIMs variaram de 0,125 a $16 \mu \mathrm{g} / \mathrm{mL}$, a CIM $_{50}$ para as amostras foi $0,5 \mu \mathrm{g} / \mathrm{mL}$ e a $\mathrm{CIM}_{90}$ foi $4,0 \mu \mathrm{g} / \mathrm{mL}$ (Tabela 1). Todas as amostras estudadas mostraram-se sensíveis ao voriconazol, e as CIMs tiveram variação de 0,03 a $0,25 \mu \mathrm{g} / \mathrm{mL}$, com $\mathrm{CIM}_{50}$ de $0,03 \mu \mathrm{g} / \mathrm{mL}$ e $\mathrm{CIM}_{90}$ de $0,125 \mu \mathrm{g} / \mathrm{mL}$ (Tabela1).

TABELA 1 - Concentrações inibitórias mínimas para anfotericina B, fluconazo e voriconazol dos isolados.

\begin{tabular}{lccc}
\hline & Anfotericina B & Fluconazol & Voriconazol \\
\hline $\mathrm{CIM}_{50}(\mu \mathrm{g} / \mathrm{mL})$ & 0,06 & 0,5 & 0,03 \\
$\mathrm{CIM}_{90}(\mu \mathrm{g} / \mathrm{mL})$ & 0,25 & 4 & 0,125 \\
\hline $\mathbf{C I M}_{50}:$ concentração inibitória mínima para 50\% das amostras testadas. & \\
$\mathbf{C I M}_{\mathbf{9 0}}$ : concentração inibitória mínima para 90\% das amostras testadas. &
\end{tabular}

\section{DISCUSSÃo}

Neste trabalho, observamos que C. albicans foi a espécie isolada com maior frequência (93,3\%) em amostras clínicas de pacientes com candidíase vaginal. Vários estudos têm evidenciado o predomínio da espécie albicans em infecções vaginais. Entretanto, com uma proporção inferior. Estes relatos incluem os estudos de Holland cols ${ }^{14}$ na Austrália (89\%), Paulisch cols ${ }^{15}$ na Áustria (87,9\%), Correa cols ${ }^{16}$ no Brasil (87\%) e Arechavala cols ${ }^{17}$ na Argentina (86\%).

Em nosso estudo, para dois isolados vaginais, identificamos duas espécies de Candida (C. albicans e C. glabrata) na mesma amostra. Estes resultados indicam uma falha no processo de seleção das colônias utilizadas na extração do material genômico. Este fato pode ser justificado pelo cultivo dos swabs vaginais ter sido realizado somente em ágar Sabouraud, onde, estas espécies apresentam colônias com características morfológicas semelhantes. Para minimizar esta interferência as amostras deveriam ter sido semeadas em um meio cromogênico, o que não ocorreu. De qualquer modo, o resultado aponta para uma possível colonização concomitante por $C$. albicans $\mathrm{e}$ C. glabrata. A maioria das vaginites é causada por uma única espécie de Candida, entretanto, duas ou mais espécies podem estar envolvidas simultaneamente neste tipo de processo infeccioso ${ }^{17-19}$.

Abordagens moleculares estão sendo desenvolvidas para estabelecer uma identificação mais rápida e segura de espécies fúngicas, devido à imprecisão e demora dos testes fenotípicos tradicionais. Estas técnicas, como o PCR, o PCR multiplex e o nested-PCR, têm permitido identificar espécies de Candida através da amplificação principalmente das regiões ITS1 e ITS2, que estão presentes em fungos patogênicos ${ }^{20,8,9}$.

Em nosso trabalho foi possível identificar as espécies de isolados de Candida utilizando um primer universal ITS4 o qual anela em uma região do gene rRNA $28 \mathrm{~S}$ e quatro primers espécie específicos, baseados nas regiões dos espaçadores transcritos internos 1 e 2 . Wahyuningsih cols ${ }^{21}$ caracterizaram C. albicans utilizando os primers ITS3 e ITS4. Fujita cols ${ }^{22}$ identificaram espécies de Candida através de um PCR multiplex, utilizando os primers universais ITS1, ITS3 e ITS4. Chang cols ${ }^{23}$ utilizaram o PCR multiplex para identificação de Candida e suas espécies. A técnica foi baseada na amplificação das regiões ITS1 do gênero Candida e de um fragmento da região ITS2, específica para C. albicans. Leaw $\operatorname{cols}^{24}$ determinaram as espécies de fungos patogênicos utilizando sequências das regiões ITS. As regiões ITS1 e ITS2 são apropriadas para o diagnóstico, identificação, taxonomina e filogenia de fungos de importância médica. Além disto, a utilização de primers universais podem beneficiar as técnicas de diagnóstico clínico microbiológico ${ }^{25-27}$.

A anfotericina B é considerada a droga de referência para o tratamento da maioria das infecções fúngicas, porém apresenta alta toxicidade e sua indicação deveria ser restrita às infecções sistêmicas ${ }^{1,28}$. Em nosso estudo, todos os isolados testados foram sensíveis a anfotericina $B$, apresentando valores de CIMs que variam de 0,03 a $0,25 \mu \mathrm{g} / \mathrm{mL}$. Outros autores também têm observado uma elevada sensibilidade a anfotericina B em amostras clínicas de espécies de Candida. Galle \& Gianini ${ }^{9}$, Ferraza cols ${ }^{1}$ e Ribeiro $\operatorname{cols}^{29}$ ao avaliarem a sensibilidade de isolados vaginais de Candida observaram valores de CIMs que variaram entre $0,25 \mathrm{a} 1 \mu \mathrm{g} / \mathrm{mL}$ e 0,12 e $1 \mu \mathrm{g} / \mathrm{mL}$ respectivamente, caracterizando suas amostras como sensíveis a anfotericina $\mathrm{B}$. 
Os triazólicos são fármacos bastante utilizados no tratamento e profilaxia das infecções fúngicas. Entretanto, existe uma tendência para se evitar o uso profilático do fluconazol em doses baixas, a fim de se prevenir o surgimento de isolados resistentes e surgimento de infecções causadas por espécies naturalmente resistentes a este antifúngico como C. grablata e C. Krusei ${ }^{9,28}$. Os valores de CIM ao fluconazol encontrados em nosso trabalho são semelhantes aos valores reportados por Galle \& Gianini ${ }^{9}$, Ferraza cols ${ }^{1}$ e Gross cols $^{30}$.

Um isolado em estudo foi caracterizado como sensível dosedependente ao fluconazol (CIM de $16 \mu \mathrm{g} / \mathrm{mL}$ ). Outros autores têm relatado o crescente número de amostras sensíveis doses dependentes a este antifúngico. Richter cols $\mathrm{s}^{31}$ ao analisarem amostras de pacientes com vulvovaginites recorrentes, encontraram CIMs para fluconazol elevados $(\mathrm{CIM} \geq 16 \mu \mathrm{g} / \mathrm{mL})$ em $15 \%$ das amostras. Mohanty $\operatorname{cols}^{32}$ observaram que $30 \%$ dos isolados de Candida da mucosa vaginal estudados foram dose-dependentes.

O voriconazol é um antifúngico triazólico de amplo espectro, reservado para tratamento de micoses sistêmicas, em nosso estudo

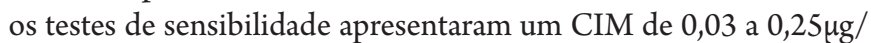
$\mathrm{mL}$, revelando sensibilidade elevada dos isolados a este antifúngico. Pfaller cols ${ }^{33}$ ao testar a sensibilidade de isolados vaginais de Candida com testes de disco difusão encontraram em espécies de C. albicans um percentual de sensibilidade elevado, de 98,4\%. Swinne cols ${ }^{34}$ em seu estudo demonstraram uma atividade elevada do voriconazol contra C. albicans, representado por $94 \%$ de sensibilidade.

Pacientes que apresentam sintomas de vulvovaginite fúngica diagnosticadas através de cultura positiva para Candida, são tratadas com terapia empírica, portanto é importante destacar que na decisão da terapêutica adequada para cada paciente, se considere não somente a patogenia, mas também as características intrínsecas desse paciente ${ }^{35}$. Os testes de suscetibilidade a antifúngicos são úteis na escolha do agente antifúngico mais apropriado para o tratamento das formas de candidíases. Entretanto, o uso destes testes na rotina laboratorial não é comum, pois estas técnicas apresentam custo elevado o que limita sua realização. Uma alternativa seria a utilização dos testes de disco difusão e o E-teste para rastreamento, sendo os métodos de diluição em caldo reservados para confirmação de resistência ${ }^{36}$.

Outro fato importante a ser destacado é o crescente aumento do número de isolados de espécies não-albicans, e a dificuldade e imprecisão dos testes fenotípicos na determinação destas espécies, assim abordagens moleculares estão sendo desenvolvidas para estabelecer uma identificação mais rápida e segura de espécies de fungos ${ }^{13}$. Futuramente, métodos moleculares baseados em técnicas de polimorfismos deverão ser aplicados para entender a dinâmica dos microorganismos infecciosos em populações humanas, interpretar o relacionamento entre comensalismo e infecção, identificar a origem de uma infecção ou monitorar a emergência de linhagens resistentes a drogas ${ }^{37}$.

\section{CONFLITO DE INTERESSE}

Os autores declaram não haver nenhum tipo de conflito de interesse no desenvolvimento do estudo.

\section{REFERÊNCIAS}

1. Ferraza MH, Maluf MLF, Consolaro MEL, Shinobu CS, Svidzinski TIE, Batista MR. Caracterização de leveduras isoladas da vagina e sua associação com candidíase vulvovaginal em duas cidades do sul do Brasil. Rev Brasi Ginec Obst $2005 ; 27: 58-63$.
2. Nyirjesy PS, Seeney M, Grody MHT, Jordan CA, Buckley HR. Chronic fungal vaginitis: the value of cultures. Am. J Obstet Gynecol 1995; 173:820-823.

3. Oliveira NC, Rampazzo RCP, Minari MC, Correa PRC, Bizerra FC, Carnneiro $\mathrm{M}$, et al. Utilização de um meio cromogênico e da técnica de semi-nested PCR para identificação de espécies de Candida. Semina: Cien Biol de Saude 2006; 27:125-132.

4. Santos IBC, Oliveira NMC, Xavier DE, Casimiro GS, Pena RLM, Lima EO Avaliação do método clássico e do CHROMagar Candida na identificação de leveduras. LAES \& HAES 2005; 56:182-192.

5. Sidrim JJC, Rocha MFG. Micologia Médica à luz de autores contemporâneos. $1^{\text {a }}$ editora Guanabara Koogan; 2004.

6. Cirak MY, Kalkanci A, Kustimur S. Use of molecular methods in identification of Candida species and evaluation of fluconazole resistance. Mem Inst Osw Cruz 2003; 8:1027-1032

7. Elie CM, Lott TJ, Reiss E, Morrison CJ. Rapid identification of Candida species with species-specific DNA probes. J Clin Microbiol 1999; 36:3260-3265.

8. Goebel CS. Padronização de ensaio imuno-enzimático (ELISA) para diagnóstico laboratorial de candidemias. Dissertação de Mestrado, Universidade Federal do Rio Grande do Sul, Porto Alegre, RS; 2007.

9. Galle LC, Gianinni MJSM. Prevalência e suscetibilidade de leveduras vaginais. Jorn Bras Patol Med Labor 2004; 40:229-236.

10. National Commitee for Clinical Laboratory Standards. Reference method for broth dilution antifungal susceptibility testing of yeasts. Approved Standard: document nº M27-A2. Wayne, PA: NCCLS; 2002.

11. Sobel JD, Zervos M, Reed BD, Hooton T, Soper D, Nyirjesy P, et al. Fluconazole Susceptibility of Vaginal Isolates Obtained from Women with Complicated Candida Vaginitis: Clinical Implications. Antimicrob Agents Chemother $2003 ; 47: 34-38$.

12. Crestani J. Isolamento e caracterização de leveduras de uma madeireira e sua correlação com um caso clínico de criptococose. Dissertação de Mestrado, Universidade Federal do Rio Grande do Sul, Porto Alegre, RS; 2007.

13. Li YL, Leaw JH, Chen H, Chang HC, Chang TC. Rapid identification of yeasts commonly found in positive blood cultures by amplification of the internal transcribed spacer regions 1 and 2. Eur J Clin Microbiol Infect Dis 2003; 22:693696.

14. Holland J, Young ML, Lee O, Chen SC-A. Vulvovaginal carriage of yeasts other than Candida albicans. Sex Transm Infect 2003; 79:249-250.

15. Paulitsch A, Weger W, Ginter-Hanselmayer G, Marth E, Buzina W. A 5-year (2000-2004) epidemiological survey of Candida and non-Candida yeast species causing vulvovaginal candidiasis in Graz, Austria. Mycoses 2006; 49:471-475.

16. Corrêa PR, David PRS, Peres NP, Cunha KC, Almeida MTG. Caracterização fenotípica de leveduras isoladas da mucosa vaginal em mulheres adultas. Rev Bras Ginecol Obstet 2009; 31:177-181.

17. Arechavala AI, Bianchi MH, Robles AM, Santiso G, Negroni R. Identificación y sensibilidad frente a fluconazol y albaconazol de 100 cepas de levaduras aisladas de flujo vaginal. Rev Iberoam Micol 2007; 24:305-308.

18. Rivera-Sanchez R, Flores Paz R, Arriaga Alba M. Identificación de especies de Candida causantes de vaginitis en población mexicana. Enferm Infecc Microbiol Clin 2006; 24:634-636.

19. Richter SS, Galask RP, Messer SA, Hollis RJ, Diekema DJ, Pfaller MA. Antifungal susceptibilities of Candida Species causing vulvovaginitis and epidemiology of recurrent cases. J Clin Microbiol 2005; 43:2155-2162.

20. Boriollo MFG. Análise da diversidade genética de amostras de Candida albicans isoladas da cavidade bucal de crianças saudáveis por eletroforese de enzima multiloco. Rev Bras Epidemiol 2005; 8:51-66.

21. Wahyuningsih R, Freisleben H, Sonntag H, Schntzler P. Simple and rapid detection of Candida albicans DNA in serum by PCR for diagnosis of invasive candidiasis. J Clin Microbiol 2000; 38:3016-3021.

22. Fujita S, Senda Y, Nakaguchi S, Hashimoto T. Multiplex PCR using internal transcribed spacer 1 and 2 regions for rapid detection and identification of yeast strains. J Clin Microbiol 2001; 39:3617-3622.

23. Chang HC, Leaw SN, Huang AH, Wu TL, Chang TC. Rapid identification of yeast in positive blood cultures by a multiplex PCR method. J Clin Microbiol $2001 ; 39: 3466-3471$. 
24. Leaw SN, Chang HC, Sun HF, Barton R, Bouchara J, Chang TC. Identification of medically important yeast species by sequence analysis of the internal transcribed spacer regions. J Clin Microbiol 2006; 44:693-699.

25. Chen YC, Eisner JD, Kattar MM, Rassoulian-Barret SL, Lafe K, Yarfitz SL, et al. Identification of medically importante yeast using PCR-based detection of DNA sequence polymorphism in the internal transcribed spacer 2 region of rRNA gene. J Clin Microbiol 2000; 38:2302-2310.

26. Mirhendi H, Makimuka K. PCR-detection of Candida albicans in blond using a new primer pair to diagnosis of systemic candidiasis. Iran J Public Health $2003 ; 32: 1-5$.

27. Henry T, Iwen PC, Hinirchs SH. Identification of Candida species using internal transcribed spacer region 1 and 2. J Clin Microbiol 2000; 38:1510-1515.

28. Marra A, Camargo LFA. Fluconazol ou anfotericina B no tratamento de candidemias em pacientes internados na UTI. Rev Assoc Med Bras 2002; 48:107.

29. Ribeiro MA, Dietze R, Paula CR, Da Matta DA, Colombo AL. Susceptibility profile of vaginal yeast isolates from Brazil. Mycopathologia. 2001;151:5-10.

30. Gross NT, Arias ML, Moraga M, Baddasarow Y, Jarstrand C. Clinical Study Species Distribution and Susceptibility to Azoles of Vaginal Yeasts Isolated Prostitutes. Infect Dis Obstet Gynecol 2007; 82:412-417.

31. Richter SS, Galask RP, Messer SA, Hollis RJ, Diekema DJ, Pfaller MA. Antifungal susceptibilities of Candida species causing vulvovaginitis and epidemiology of recurrent cases. J Clin Microbiol 2005; 43:2155-2162.

32. Mohanty S, Xess I, Hasan F, Kapil A, Mittal S, Tolosa JE. Prevalence e susceptibility to fluconazol of Candida species causing vulvovaginitis. Indian Med Resid 2007; $126: 216-219$

33. Pfaller MA, Diekema DL, Gibbs VA, Newell JF, Meis IM, Gould WF, et al. Results from the artemis disk global antifungal surveillance study, 1997 to 2005: an 8.5-year analysis of susceptibilities of Candida species and other yeast species to fluconazole and voriconazole determined by CLSI standardized disk diffusion testing. J Clin Microbiol 2007; 45:1735-1745.

34. Swinne D, Watelle M, Nolard N. In vitro activities of voriconazole, fluconazole, itraconazole and amphotericin B against non Candida albicans yeast isolates. Rev Iberoam Micol 2005; 22:24-28.

35. Fidel PL, Sobel JD. Immunopathogenesis of recurrent vulvovaginal candidiasis. Clin. Microbiol Rev 1996; 9:335-348.

36. VermitskyJP, Self MJ, Chadwick SG, Trama JP, Adelson ME, Eli M, et al. Survey of Vaginal-Flora Candida Species Isolates from Women of Different Age Groups by Use of Species-Specific PCR Detection. J Clin Microbiol 2008; 46:1501-1503.

37. Boriollo MFG, Hofling JF, Mendes A, Rosa EAR. Ferramentas moleculares para caracterização de Candida albicans (Robin) Berkout (1923) em estudos epidemiológicos. Est Biol 2005; 27:21-47. 